\title{
METHODS FOR MEASURING THE• RESISTANCE AT ANY POINT ON THE BODY AND FOR EQUALIZING INEQUALITIES OF SKIN RESISTANCE
}

\author{
BY
}

\section{EMANUEL GOLDBERGER}

\begin{abstract}
From the Electrocardiographic Department, Lincoln Hospital, New York, N.Y.
\end{abstract}
Received April 12, 1951

\section{For Measuring the Resistance at any Point in the Body}

When standard leads or ordinary præcordial leads are taken with a string galvanometer electrocardiograph, the resistance of the patient can be measured for each lead. However, no method has been described previously by which the resistance at any of the extremities or at any point on the body can be measured. A method for doing this is described below.

Principle. When the standard leads are taken, the resistance of the patient as measured consists of the resistance of the skin at the points of electrode contact and the resistance of the body tissues and fluids. Thus, the resistance of the patient measured from lead I includes the resistance of the point of right-arm electrode contact, the resistance of the point of left-arm electrode contact, and the resistance of the body tissues and fluids. Similar situations hold for the resistances of the patient when lead II, III, or any bipolar lead is taken. However, for the purposes of this paper, we shall assume that practically all the resistance of the patient is centred at the two points of extremity-electrode contact for each lead. Studies have been made which indicate that the resistance of the body tissues and fluids is at most only a few hundred ohms (Richter and Woodruff, 1941). Even if the resistance of the body fluids and tissues were of magnitude, this would only change the results quantitatively but not qualitatively because the resistances of the body fiuids and tissues are equal (Kaufman and Johnston, 1943).

Thus, if the resistance, $R$, of lead I as measured is $700 \mathrm{ohms}$, of lead II, $1000 \mathrm{ohms}$, and of lead III, $1100 \mathrm{ohms}$, the following relations would hold:

Therefore,

$$
\begin{aligned}
R_{I} & =R_{L A}+R_{R A} . \\
R_{I I} & =R_{L I}+R_{R A} . \\
R_{I I I} & =R_{L L}+R_{L A} .
\end{aligned}
$$

$$
R_{I}+R_{I I}=\left(R_{L A}+R_{R A}\right)+\left(R_{L L}+R_{R A}\right)=2 R_{R A}+R_{L A}+R_{L L} \text {. }
$$

However, $R_{L A}+R_{I L}=R_{I I I}$, therefore

$$
\begin{array}{ll}
2 R_{R A}+R_{I I I} & =R_{I}+R_{I I}, \text { or } \\
2 R_{R A} & =R_{I}+R_{I I}-R_{I I I}, \text { and } \\
R_{R A} & =\left(R_{I}+R_{I I}-R_{I I I}\right) / 2 .
\end{array}
$$

Similar analysis yields the following formulae for the resistances of the left arm and left leg:

$$
\begin{aligned}
& R_{L A}=\left(R_{I}+R_{I I I}-R_{I I}\right) / 2 \quad \text {. . . . . . (2) } \\
& R_{L L}=\left(R_{I I}+R_{I I I}-R_{I}\right) / 2 \quad \text {. . . . . . . (3) }
\end{aligned}
$$

Using these formulae, we find that with the above example $R_{R A}=300$ ohms; $R_{L A}=400$ ohms; $R_{\text {LI }}=700$ ohms. 
Thus, the resistance at the right arm, left arm, or left leg can be determined merely by measuring the patient resistances in the three standard leads, and using formulae (1), (2), and (3). The resistance of any three points of the body can be measured in a similar way.

The patient resistance in any standard lead can be quickly and easily measured according to the following formula (Royce, 1949):

$$
R_{P}=\left(2000+R_{s}(1-d)\right) / d \text {. }
$$

where $\mathbf{R}_{\mathbf{p}}$ is the resistance of the patient in the particular lead being taken, $\mathbf{R}_{s}$ is the resistance of the particular string in the electrocardiograph, and $d$, is the deflection of the string in centimetres. 1 represents a $1-\mathrm{cm}$. deflection of the string, the electrocardiograph having been standardized in the usual way so that $1 \mathrm{mv}$. produces a $1-\mathrm{cm}$. deflection.

In order to use this formula, tracings are taken in the following way. (1) The electrocardiograph is standardized in the usual way and a tracing taken of the string deflection when $1 \mathrm{mv}$. is introduced, with the patient out of the circuit. (2) Leads I, II, and III are then taken without changing the standardization. However, while each lead is taken, a $1-\mathrm{mv}$. potential is introduced into the circuit and the string deflection recorded.

In making actual measurements, a 2-mv. potential was introduced for standardization instead of a 1-mv. potential to achieve greater accuracy, so that the $2 \mathrm{mv}$. produced a standardization deflection of $2 \mathrm{~cm}$. instead of $1 \mathrm{~cm}$. Therefore the above formula was modified in the following way:

$$
R_{P}=\left(4000+R_{s}(2-d)\right) / d
$$

Example. Fig. 1 shows an actual electrocardiogram taken in this way. The resistance of the string was $2100 \mathrm{ohms}$. Notice that the standardization deflection was $2 \mathrm{~cm}$.; that of lead I, $2 \cdot 2 \mathrm{~cm}$.; lead II, $1.5 \mathrm{~cm}$; and lead III, $1.4 \mathrm{~cm}$. Using the above formula, (5), the resistances of the leads are $R_{I}=$ about 1627 ohms, $R_{I I}=$ about 3366 ohms, and $R_{I I I}=$ about 3757 ohms.

And from formulae (1), (2), and (3), we find that $R_{R A}=618$ ohms; $R_{L A}=1009$ ohms; and $R_{L L}$ $=2748 \mathrm{ohms}$.

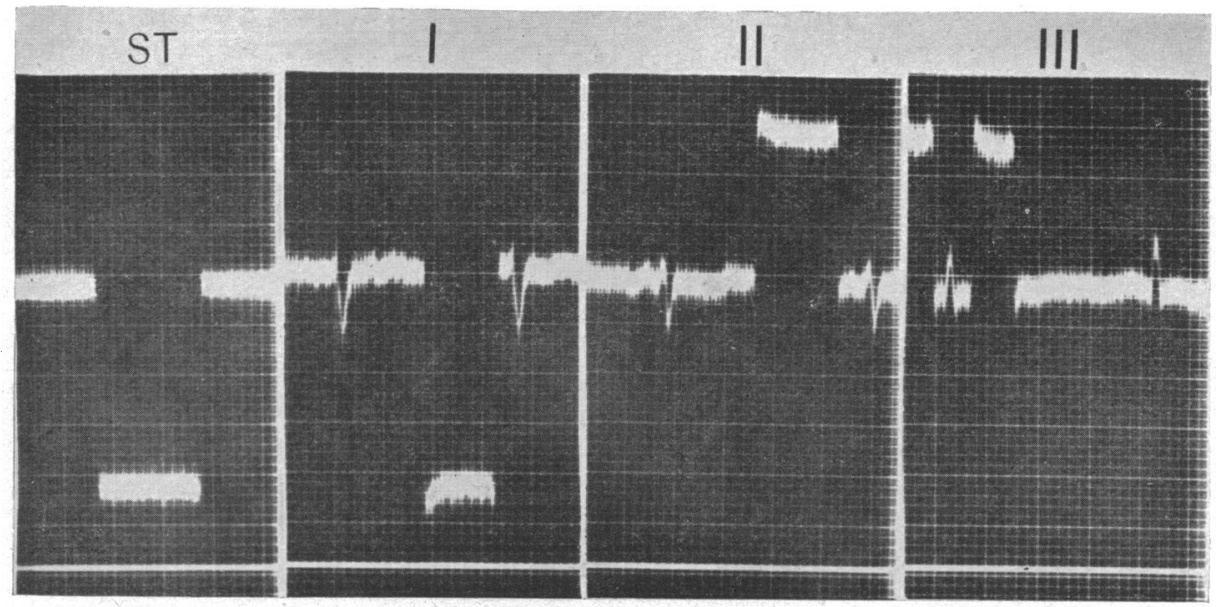

FIG. 1.-Tracings showing how skin resistance can be measured. ST, the deflection of the string galvanometer when a potential of $2 \mathrm{mv}$. was introduced with the patient out of the circuit; I, II, III, the deflections produced when the same potential was introduced while leads I, II, and III were being recorded. (Also see text.)

Summary. A method is described of measuring the skin resistance at any point of electrode contact, using a string galvanometer electrocardiograph. Studies on the significance of marked variations in skin resistance with respect to the deflections of unipolar leads are now in progress. 


\section{For Equalizing Inequalities of Skin Resistance}

The use of a central terminal (with or without resistors) in taking unipolar leads, depends on, among other things, the near equality of the skin resistance under the electrode at each extremity. In order to determine what effect, if any, complete equality of skin resistance has on the deflections of unipolar leads, the following method of equalizing skin resistance was developed.

Principle. A string galvanometer electrocardiograph is standardized by introducing a standardization potential of $1 \mathrm{mv}$. into the circuit and varying the tension of the string to produce a standard deflection of $1 \mathrm{~cm}$. $(10 \mathrm{~mm}$.). When leads I, II, and III are being recorded and the standardization potential of $1 \mathrm{mv}$. is introduced, the deflection that results will vary, more or less than $1 \mathrm{~cm}$., depending on the variations in skin resistance beneath the electrode on each extremity. If the amplitudes of these standardization deflections are measured, a result such as the following may be obtained:

Standardization deflection with patient out of circuit. . $\quad . . \quad \ldots 10 \mathrm{~mm}$.

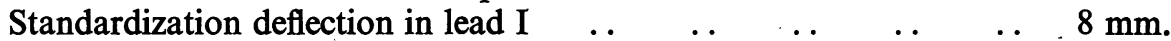

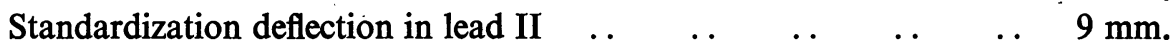

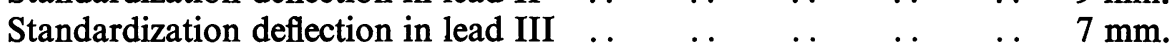

It is possible to construct a table showing, for example, that when the amplitudes of the standardization deflections in the standard leads are as above, namely III $<$ I $<$ II, the qualitative relationships between the actual resistances, $R$, at each extremity would be $R$ right arm $<R l e f t$ leg $<$ Rleft arm. This, of course, gives no indication of the actual resistance at each extremity. However, if potentiometers (variable resistors) are introduced into the circuit between each lead cable of the electrocardiograph and the patient (Fig. 2), and the potentiometers adjusted until the amplitudes

Table ShOWING the Relative Resistances at THE EXTREMITIES WITH VARYING RelationshIPS BetWeEN THE AMPLITUdes OF THE StandaRdization Deflections IN THE

THREe STANDARD LeadS

\begin{tabular}{|c|c|}
\hline $\begin{array}{l}\text { Relative amplitudes of } \\
\text { standardization deflections }\end{array}$ & $\begin{array}{l}\text { Relative values of } \\
\text { skin resistance }\end{array}$ \\
\hline $\mathrm{I}=\mathrm{II}=\mathrm{III}$ & $\mathrm{RA}=\mathrm{LA}=\mathrm{LL}$ \\
\hline $\mathrm{I}<\mathrm{II}<\mathrm{III}$ & $\mathrm{LL}<\mathrm{LA}<\mathrm{RA}$ \\
\hline $\mathrm{I}<\mathrm{III}<\mathrm{II}$ & $\mathrm{LL}<\mathrm{RA}<\mathrm{LA}$ \\
\hline $\mathrm{II}<\mathrm{III}<\mathrm{I}$ & $\mathrm{LA}<\mathrm{RA}<\mathrm{LL}$ \\
\hline II $<$ I $<$ III & $\mathrm{LA}<\mathrm{LL}<\mathrm{RA}$ \\
\hline $\mathrm{III}<\mathrm{II}<\mathrm{I}$ & $\mathrm{RA}<\mathrm{LA}<\mathrm{LL}$ \\
\hline III $<$ I $<$ II & $\mathrm{RA}<\mathrm{LL}<\mathrm{LA}$ \\
\hline $\begin{array}{c}\text { II }<{ }^{*} \\
\text { III }\end{array}$ & $L L<\underset{\substack{\mathrm{RA} \\
=}}{=}$ \\
\hline $\mathrm{II}<\stackrel{\text { III }}{=}$ & $\mathrm{LA}<\underset{\substack{\mathrm{RA} \\
\mathbf{L L}}}{=}$ \\
\hline III $<\underset{\text { II }}{\text { II }}$ & 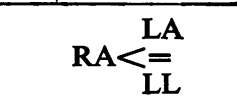 \\
\hline
\end{tabular}

* The converse of these three are of course equally valid.

Right arm, RA; left arm, LA; and left leg, LL.

$<$, less than; $>$, more than; $=$, equal to. 
of the standardization deflection in each lead ąre identical (regardless of the actual amplitude of the standardization deflections which result) the total resistance at each extremity (skin resistance plus the resistance of the potentiometer) will be identical.

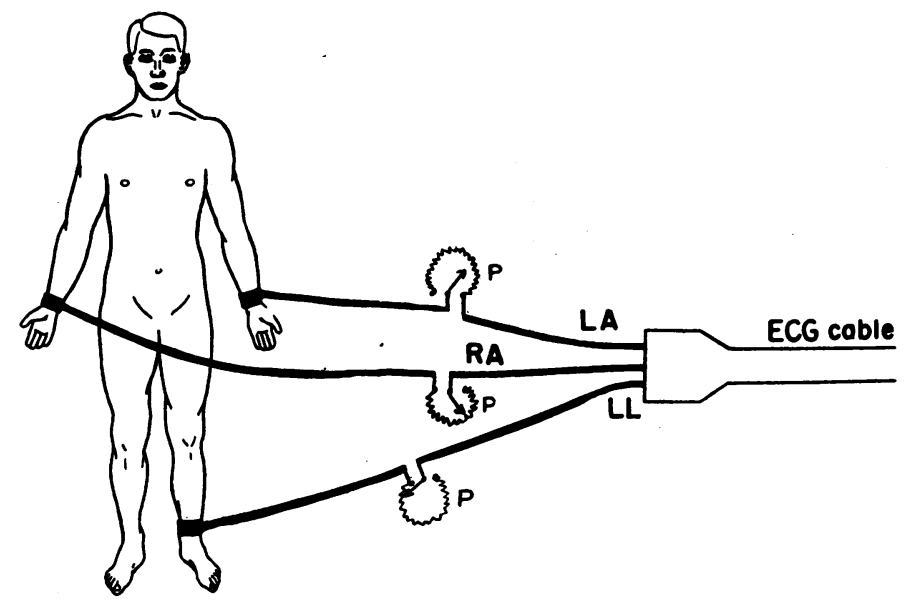

FIG. 2.-Diagram showing how potentiometers are introduced into the circuit to equalize skin resistance. $\mathbf{P}$, potentiometer (variable resistor). (Also see text.)

Although the resistances of the potentiometers can be varied by a trial-and-error method until the standardization deflections are equal in all three leads, the use of the data in the Table is advantageous because it enables the investigator to increase the resistances of at most two extremitiesthose with the lowest skin resistance. In actual operation, the potentiometers were mounted in a box, as shown in Fig. 3.

Example. Fig. 4 and 5 show a tracing taken in this way. In Fig. 4 , notice that the standardization deflection of the string when the patient is out of the circuit is $2 \mathrm{~cm}$., not $1 \mathrm{~cm}$. This is due to the fact that a standardizing potential of $2 \mathrm{mv}$. was introduced into the circuit, and the string deflection adjusted to a standard of $2 \mathrm{~cm}$. to achieve greater accuracy in measurement. Notice

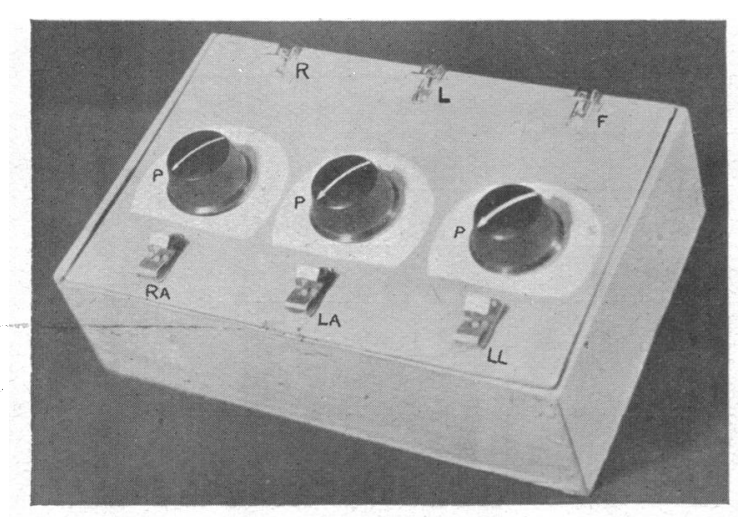

A

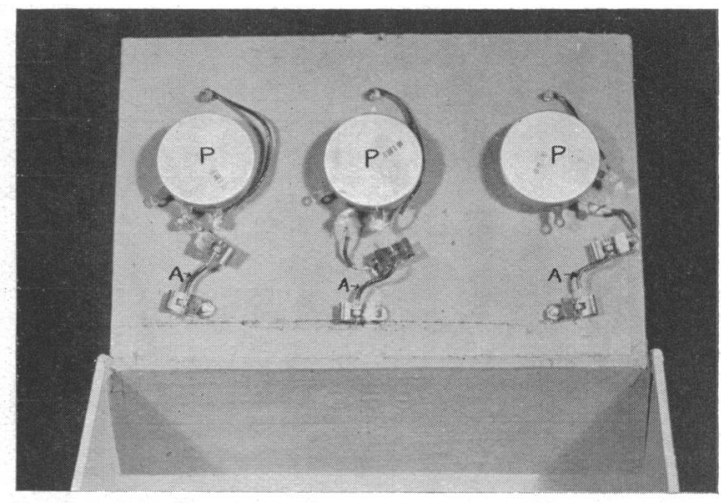

B

Fig. 3.-(A) Assembly box housing the potentiometers, R, L, F, clips into which are inserted the three lead cables of the electrocardiograph; P, knobs of the potentiometers; RA, LA, LL, clips into which are inserted wires (not shown) which are attached to the three extremities.

(B) Under surface of cover of box shown in figure 3 (A). P, potentiometers with a maximum value of $1000 \mathrm{ohms}$. Since differences in skin resistance between the extremities may exceed 1000 ohms, provision was made to insert additional fixed resistors, if necessary, at points, A. 


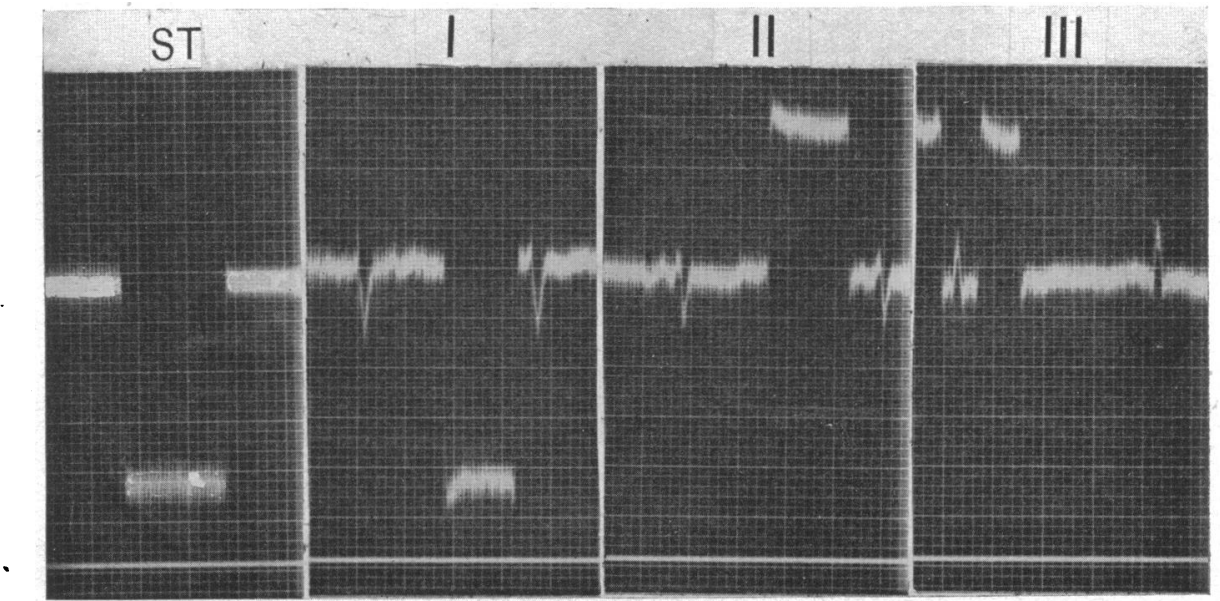

FIG. 4.-This shows a tracing taken before the skin resistances were equalized. ST, shows the standardization deflection when a potential of $2 \mathrm{mv}$. was introduced with the patient out of the circuit. I, II, III, show the deflections produced when the same potential was introduced while the leads were being recorded. Notice that the amplitudes of the standardization deflections are different in each lead.

also that the standardization deflections in the three standard leads are not only less than $2 \mathrm{~cm}$. (because of the skin resistance) but differ in each lead, due to the inequalities of skin resistance.

Fig. 5 shows the three standard

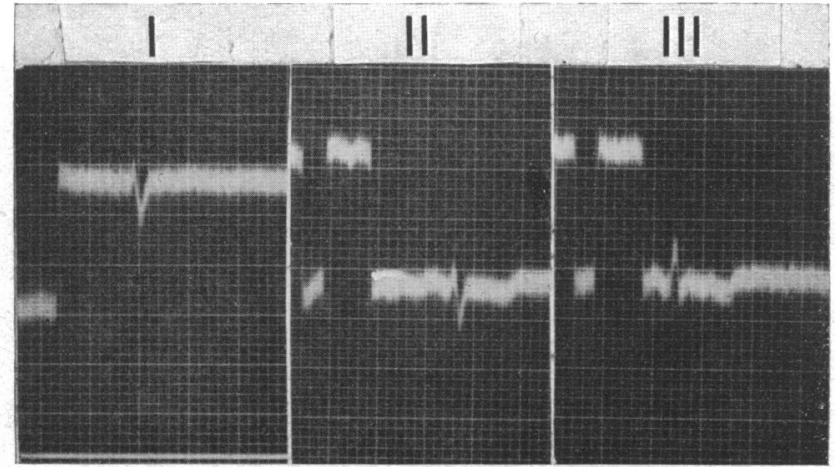

Fig. 5.-This shows the same electrocardiogram taken after the skin resistances had been equalized. leads taken after the resistances in the extremities had been equalized with the method described above. The standardization deflection with the patient out of the circuit (not shown) is still $2 \mathrm{~cm}$. When the three standard leads are taken, the standardization deflection is now much less than $2 \mathrm{~cm}$. due to the resistances which have been added, but it is now equal in all three leads, because the total resistances have been equalized. The actual value of the resistances added to the circuit, and the actual resistance at each extremity can be easily calculated using the method described in the first part.

Summary. A method is described for equalizing inequalities of skin resistance using a string galvanometer electrccardiograph. Studies of the effect of equalizing skin resistance on the deflections of unipolar leads are now in progress.

The author wishes to express his appreciation to Stan Rakoff and Allen Zimmer for their help in this project.

\section{REFERENCES}

Kaufman, W., and Johnston, F. D. (1943). Amer. Heart J., 26, 42.

Richter, C. P., and Woodruff, B. G. (1941). Surgery, 10, 957.

Royce, K. P. (1949): Cambridge Instrument Co., New York; personal communication to the author. 